\title{
Internet Oyun Oynama Bozukluğu Olan Adölesanlarda Kas İskelet Sistemi Semptomları
}

\section{Musculoskeletal Symptoms in Adolescents with Internet Gaming Disorders}

\author{
Aybike Şenel 1(D), Elçin Atılgan 2(D), Merve Turhan 2(D), Rümeysa Özsoy 2(D), Sümeyra

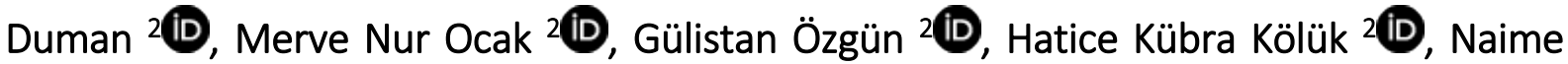 \\ Simla Sünmez 2,3(D), Caner Mutlu 4(D), Ebru Kaya Mutlu 2(D)
}

\footnotetext{
1. İstanbul Üniversitesi-Cerrahpaşa, Lisansüstü Eğitim Enstitüsü Fizyoterapi ve Rehabilitasyon Anabilim Dalı, İstanbul

2. İstanbul Üniversitesi-Cerrahpaşa, Sağlık Bilimleri Fakültesi Fizyoterapi ve Rehabilitasyon Bölümü Dalı, İstanbul

3. Doğu Akdeniz Üniversitesi Lisansüstü Eğitim Enstitüsü Fizyoterapi ve Rehabilitasyon Anabilim Dalı, Mağusa, KKTC

4. Başakşehir Çam ve Sakura Şehir Hastanesi, İstanbul
}

\section{Abstract}

Objective: The aim of this study was to examine the musculoskeletal symptoms in adolescents with internet gaming disorder (IGD).

Method: A total of 80 participants were included to this prospective cross-sectional study. Participants were divided into two equal groups: healthy adolescents and adolescents diagnosed with IGD. After sociodemographic data were recorded, musculoskeletal symptoms of the participants were evaluated with a 26-question form which was prepared by the researchers. The severity of addiction of the participants was evaluated with Internet Addiction Scale.

Results: The mean age was found 14,50 \pm 2,10 in Group I, and 14,90 \pm 1,72 in Group II with no significant difference between. The participants who agreed to the items "I do not pay attention to my pain while I am playing games" and "I feel my posture getting worse while I am playing games" were found statistically significant higher in Group II than in Group I. No significant difference was found between healthy adolescents and adolescents with IGD in terms of musculoskeletal symptoms.

Conclusion: It can be intrepreted that adolescents with IGD could not report realistically of their symptoms that they already do not pay attention while they are playing games.

Keywords: Adolescent, internet gaming disorder, musculoskeletal system, addiction

Öz

Amaç: Bu çalışmanın amacı internet oyun oynama bozukluğu (I0OB) olan adölesanlarda kas iskelet sistemi semptomlarını incelemektir.

Yöntem: Prospektif kesitsel tipte olan bu çalışmaya toplam 80 katılımcı dahil edildi. Katılımcılar sağlıklı adölesanlar ve IOOB tanısı alan adölesanlar olmak üzere iki eşit gruba ayrıldı. Sosyodemografik veriler kaydedildikten sonra, katılımcıların kas iskelet sistemi semptomları araştırmacılar tarafından hazırlanan 26 soruluk bir form ile değerlendirildi. Katıımcıların bağımlılık şiddeti İnternet Bağımlılı̆ı Ölçeği ile değerlendirildi.

Bulgular: Yaş ortalaması Grup I için 14,50 \pm 2,10 yll, Grup II için ise 14,90 \pm 1,72 yll olarak bulundu. "Oyun oynarken ağrılarımı umursamıyorum" ve "Oyun oynarken duruşumun bozulduğunu hissediyorum" maddelerine katılan katılımcılar Grup II'de Grup l'e göre istatistiksel olarak anlamlı yüksek bulundu. Kas iskelet sistemi semptomları açısından sağlıkı ve IOOB tanısı olan adölesanlar arasında anlamlı bir fark bulunmadı.

Sonuç: Bu durum, IOOB tanısı olan adölesanların, oyun oynarken semptomlarına dikkat etmemeleri nedeniyle semptomlarını gerçekçi bir şekilde rapor edemedikleri şeklinde yorumlanabilir.

Anahtar kelimeler: Adölesan, internet oyun oynama bozukluğu, kas iskelet sistemi, bağımlılık 


\section{Giriş}

Otuz yılı aşkın bir zamandır dünyanın gündeminde yer tutmaya başlayan video ve bilgisayar oyun bağımlılı̆̆, internet oyunlarının yaygınlaşmasıyla birlikte son yirmi yıldır özellikle adölesanlar için tüm dünyada hızla yaygınlaşan bir halk sağlığı sorunu halini almıştır (1). İnternet oyunları yaygınlaştıkça özellikle adölesanlarda oyunla aşırı meşguliyet, oyun başında geçirilen zamanın giderek artması, görev ve sorumlulukların inmal etme, oyundan ayrımayı tolere edememe, gerçek hayattan uzaklaşma ve sosyal izolasyon ile karakterize bir tablo izlenmeye başlanmış; ilk defa 1995'te Ivan Goldberg tarafından DSM-4 madde bağımlılı̆̆ kriterleri modifiye edilerek İnternet Bağımlılı̆ı Bozukluğu tanımlanmıştır (2). Yeni yayınlanan DSM-5'te bunlara ilave olarak Internet Oyun Oynama Bozukluğu (I00B); ileri araştırmalar gerektiren durumların yeni sınıflandığı üçüncü bölüme dahil edilmiştir (3).

Adölesanların uzun süre hareketsiz olarak teknolojik cihazlarla vakit geçirmeleri büyük ve küçük kas becerileri, el ve göz koordinasyonu gibi kaba ve ince motor gelişimlerini olumsuz etkilemektedir (4). Bu nedenle, adölesanlarda potansiyel kas-iskelet sistemi rahatsızıklarını ve sedanter yaşam tarzını en aza indirgemek için teknolojik cihazların kullanılması yerine oyuncakla oynamanın teşvik edilmesi gerektiği bildirilmiştir (5). Adölesanların teknolojik cihazlarla erken yaşlardan itibaren tanışmış olması ve teknolojik ürünlerin yetişkinlere göre tasarlanmış olmasından dolayı kas-iskelet sistemi sorunları bakımından yetişkinlerden daha fazla risk altında olduğu bildirilmiştir (6). Bu nedenle, IOOB tanılı adölesanlarda uzun süreli teknolojik cihaz kullanımına bağlı olarak kas iskelet sistemi sorunları görülme olasılığı yüksektir.

Literatür araştııılı̆̆ında, internet kullanıcılarında yapılan araştırmalarda kas iskelet problemleri genel olarak değerlendirilmiş, vücut bölümleri ve problemler detaylı incelenmemiştir. İnternet bağımlıları ile bağımlı olmayan internet kullanıcıları arasındaki kas iskelet sistemi problemlerini karşılaştıran çalışmalar yok denecek kadar azdır. Ayrıca, çalışmalar erişkinler üzerine olup, I00B tanısı almış adölesanlar üzerinde yapılan çalışmaya rastlanmamıştır. Bu kısıtlamalardan dolayı bu çalışma planlanmıştır. Çalışmamızın amacı; IOOB tanısı alan ve almayan 12-17 yaş arası adölesanlarda var olan kas-iskelet sistemi semptomlarını araştırmaktır.

\section{Yöntem}

\section{Örneklem}

Prospektif kesitsel tipte olan bu araştırmanın örneklemi; İstanbul Başakşehir Çam ve Sakura Şehir Hastanesi Çocuk ve Ergen Ruh Sağlığı ve Hastalıkları Polikliniği'ne problemli internet kullanımı ya da diğer sebepler nedeniyle ilk kez başvurmuş, daha önce bilinen psikiyatrik tanısı ve psikotrop ilaç kullanımı olmayan 12-17 yaş arasında psikiyatrik görüşme sonucunda IOOB tanısı almış adölesan ve aynı yaş grubundaki sağlıkı kontrollerden oluşmaktadır. Sağlıklı kontroller grubunu, polikliniğe başvuranlardan psikiyatrist hekimin (Doç. Dr. Caner Mutlu) herhangi bir tanı koymadığı ve başvuranlar ile gelen ve dahil etme kriterlerine uyan akranları oluşturmaktadır. Kas iskelet sistemine ait bir tanısı ve anketlere verilen yanıtların doğruluğunu etkileyecek kognitif problemi olan gönüllüler çalışma dışı bırakılmıştır. Örneklem büyüklüğü, 20000 popülasyon ve I00B görülme sıklığı \%1,6-\%5,1 olduğu düşünülerek \%90 güven aralığında güç analizi Rasoft Sample Size Calculator ile hesaplandığında, 40 i00B'li adölesan ve aynı yaş grubundaki 40 sağlıklı adölesan olmak üzere toplam en az 80 gönüllüye ulaşılması gerektiği hesaplanmıştır. Çalışmamızda eksik doldurulan veya tamamlanmayan anketler göz önüne alınarak her bir grup için 44 gönüllü ve toplamda 88 gönüllü alınması planlanmıştır.

\section{İşlem}

$\mathrm{Bu}$ araştırmanın gerçekleştirilmesi için, İstanbul Üniversitesi-Cerrahpaşa Girişimsel Olmayan Klinik Araştırmalar Kurulu'ndan 2020-29 sayılı etik kurul onayı 04.11.2020 tarihinde alınmıştır. Bu araştırma Helsinki Bildirgesi'ne uygun olarak yürütülmüştür. Tüm katılımcılardan sözel, yasal vasilerinden ise yazılı 
bilgilendirilmiş onam alınmış, gönüllü olur formunu doldurması talep edilmiştir. Değerlendirme amacıyla oluşturulan anketler; İstanbul Başakşehir Çam ve Sakura Şehir Hastanesi Çocuk ve Ergen Ruh Sağlığı ve Hastalıkları Polikliniği'nden yönlendirilen vakalar ve sağlıkı kontrollerine yardımcı araştırmacılar tarafından yüz yüze olarak uygulanmıştır.

\section{Veri Toplama Araçları}

Sosyodemografik veriler sorgulandıktan sonra katılımcılara, İnternet Bağımlıı̆̆ı Ölçeği ve literatür doğrultusunda araştırmacılar tarafından oluşturulmuş kas iskelet sistemine yönelik değerlendirme anketi uygulanmıştır.

\section{Sosyodemografik Veri Formu}

Katılımcıların yaş, cinsiyet, boy, kilo ve öğrenim durumu sosyodemografik veri formuna kaydedilmiştir. Ayrıca kendilerine ait oda varlığı, bilgisayar/tablet/oyun konsolu vb. uyuduğu odada durup durmaması, bilgisayar, telefon, tablet vb. üzerinden oyun oynama durumu "Evet" ve "Hayır" olarak sorgulanarak veri formuna eklenmiştir. Sosyodemografik veriler, katıımcının yanında bulunan velisinin gözetimi altında ve gerektiğinde katkıları ile kaydedilmiştir.

\section{Kas İskelet Sistemi Sorgulama Formu}

Katılımcıların kas iskelet sistemine ait ağrı, karıncalanma, uyuşukluk, güçsüzlük, kramp, tutukluk, krepitasyon varlığı, duruş bozukluğu gibi semptomlar araştırmacılar tarafından literatür doğrultusunda hazırlanmış sorularla değerlendirilmiştir. Katılımcıların kas iskelet sistemi semptomlarının sorgulandığı her maddeyi "Evet", "Nadiren" veya "Hayır" olarak yanıtlamaları istenmiştir (EK-1). Katılımcıların yanıtları yüzdelik olarak belirlenerek iki grup arasındaki farkın anlamlıı̆ı istatistiksel olarak değerlendirilmiştir.

\section{İnternet Bağımlıı̆̆ Ölçeği}

Katılımcıların genel internet bağımlıığını ve internet oyun oynama bozukluğunu tanımlayabilmek için toplam 20 maddeden oluşan likert tipte bir ölçek olan İnternet Bağımlı̆̆g Ölçeği kullanılmıştır. Katılımcılardan her maddeyi "Nadiren (1)", "Ara ara (2)", "SIk sık (3)", "Çoğu zaman (4)" veya "Her zaman (5)" olarak yanıtlamaları istenmiştir. Testten alınabilecek en düşük puan 20, en yüksek puan 100'dür. 80 ve üzeri puan almak işlevsellikte belirgin bozulmanın göstergesi kabul edilmekte ve bu grup "internet bağımlıı" olarak tanımlanmaktadır. "49 puan ve altı" alanlar ise yaşamında internet kullanımına bağlı herhangi sorun yaşamayan "ortalama internet kullanıcısı" olarak tanımlanmaktadır. Ölçek orijinal olarak Young tarafından geliştirilmiştir (7). Ölçeğin, Türkçe geçerlik ve güvenirliği Bayraktar (2015) tarafından adölesanlar üzerinde yapılmış, Cronbach alfa iç tutarlık katsayısı 0,91 olarak bulunmuştur (8). İnternet Bağımlıığı Öıçeği'nin bu çalışmadaki Cronbach alfa değeri 0,93 bulunmuştur.

\section{Veri Analizi}

Veriler istatistiksel olarak SPSS (Statistical Package for Social Scieneces) 20.0 versiyonu ile analiz edildi. Verilerin normal dağılıma uygunluğunun tespiti için Shapiro Wilk Testi kullanıldı. Tüm veriler normal dağılıma uyduğu için analizde parametrik testler uygulandı. Tüm analizlerde $p<0.05$ (iki yönlü) değerler istatistiksel olarak anlamlı kabul edildi. Çalışmanın istatistiksel analizinde, ele alınan değişkenler ortalama, standart sapma ve yüzde değerleri ile tanımlandı. Gruplar, demografik, klinik özellikleri ve kas iskelet sistemi problemleri Mann-Whitney U ve Ki-kare Testi kullanılarak karşılaştırıldı.

\section{Bulgular}

Çalışmamızda 12-17 yaş aralığında toplam 80 katılımcı değerlendirilmiştir. Katılımcılar IOOB tanıSı olmayanlar (Grup I; $n=40$ ) ve IOOB tanısı olanlar (Grup II; n=40) olmak üzere iki gruba ayrılmıştır. Grup I'de 14'u kadın, 26'i erkek olmak üzere toplamda 40; Grup Il'de ise kişilerin 7'si kadın; 33'ü erkek olmak üzere toplam 40 katılımcı bulunmaktadır. Katılımcıların yaş ortalamaları; Grup I için 14,50 $\pm 2,10$ yıl ve Grup II için 14,90 $\pm 1,72$ yıldır. Grupların yaş ortalamaları arasındaki fark istatistiksel olarak anlamsız bulunmuştur 
$(\mathrm{p}=0,48)$. İki grubun da \%47,5'inin ilkokulda, \%52,5'inin ise lisede okuduğu tespit edilmiştir. İnternet Bağımlıl̆ğ Ölçeği skor ortalaması Grup I için 40,52 \pm 14,28, Grup II için 59,57 \pm 19,78 olarak bulunmuştur. Grupların İnternet Bağımlıı̆̆ Ölçeği skor ortalamaları arasındaki fark istatistiksel olarak anlamlı bulunmuştur. Katılımcıların sosyodemografik verilerine ait ortalama ve yüzde değerleri sırasıyla Tablo 1'de verilmiştir ( $p>0,05)$.

Tablo 1. Katılımcıların sosyodemografik verilerive ölçek skorları

\begin{tabular}{|c|c|c|c|}
\hline \multirow[t]{2}{*}{ Değişkenler } & Grup I $(n=40)$ & Grup II $(n=40)$ & $P$ \\
\hline & Ort \pm SS & Ort \pm SS & \\
\hline Yaş (yll) & $14,50 \pm 2,10$ & $14,90 \pm 1,72$ & 0,48 \\
\hline VKi $\left(\mathrm{kg} / \mathrm{m}^{2}\right)$ & $20,43 \pm 3,93$ & $21,79 \pm 3,82$ & 0,08 \\
\hline \multirow{2}{*}{$\begin{array}{l}\text { Internet Bağımlılığı } \\
\text { Ölçeği Skoru }\end{array}$} & $40,52 \pm 14,28$ & $59,57 \pm 19,78$ & $0,0001^{*}$ \\
\hline & $n(\%)$ & $\mathrm{n}(\%)$ & \\
\hline Cinsiyet & & & 0,07 \\
\hline Kadın & $14(35,0)$ & $7(17,5)$ & \\
\hline Erkek & $26(65,0)$ & $33(82,5)$ & \\
\hline Öğrenim Derecesi & & & 1,00 \\
\hline İlkokul & $19(47,5)$ & $19(47,5)$ & \\
\hline Lise & $21(52,5)$ & $21(52,5)$ & \\
\hline Kendine ait oda varlığı & & & 0,28 \\
\hline Var & $33(82,5)$ & $29(72,5)$ & \\
\hline Yok & $7(17,5)$ & $11(27,5)$ & \\
\hline \multicolumn{3}{|c|}{ Bilgisayar/tablet/oyun konsolu vb. uyuduğunuz odada mı duruyor? } & 0,36 \\
\hline Evet & $22(55,0)$ & $26(65,0)$ & \\
\hline Hayır & $18(45,0)$ & $14(35,0)$ & \\
\hline \multicolumn{3}{|c|}{ Oyun oynuyor musunuz? (Bilgisayar, telefon, tablet vb. üzerinden) } & 0,53 \\
\hline Evet & $33(82,5)$ & $35(87,5)$ & \\
\hline Hayır & $7(17,5)$ & $5(12,5)$ & \\
\hline
\end{tabular}

$\mathrm{P}^{*}$ : Mann Whitney Testi $\mathrm{P}^{\star *}$ : Pearson Ki-Kare Testi SS: Standart Sapma Ort: Aritmetik Ortalama

Katıımcıların Kas İskelet Sistemi Sorgulama Formu'na verdikleri yanıtların tümü Tablo 2'de gösterilmiştir. "Oyun oynarken ağrılarımı umursamıyorum." maddesine Grup I'in \%20'si "Evet”, \%70'i "Hayır", \%10'u "Nadiren"; Grup II'nin \%50'si "Evet", \%37,5'i "Hayır, \%12,5'i "Nadiren" yanıtı verdiği görülmüștür. Grupların bu madde için verdiği yanıtlar arasında istatistiksel olarak anlamlı fark tespit edilmiştir $(p<0,01)$ (Tablo 2).

"Oyun oynarken duruşumun bozulduğunu hissediyorum." maddesini, Grup l'in \%30'unun"Evet", \%42,5'inin "Hayır", \%27,5'inin "Nadiren"; Grup II'nin \%57,5'inin "Evet”, \%30'unun "Hayı", \%14,5'inin "Nadiren" olarak yanıtladığı görülmüştür. Grupların bu maddeye verdikleri yanıtlar arasında istatistiksel olarak anlamlı farklıık tespit edilmiştir $(p<0,03)$. Katılımcıların diğer kas iskelet sistemi problemlerine ait yanıtları arasında anlamlı bir farkılık bulunmamıştır $(p>0,05)$ (Tablo 2).

Tablo 2. Kas-iskelet sistemi problemlerine ait veriler

\begin{tabular}{|c|c|c|c|}
\hline $\begin{array}{l}\text { Kas-Iskelet Sistemi } \\
\text { Sorgulama Formu }\end{array}$ & $\begin{array}{c}\text { Grup I } \\
(n=40) \\
n(\%)\end{array}$ & $\begin{array}{c}\text { Grup II } \\
(n=40) \\
n(\%)\end{array}$ & P \\
\hline \multicolumn{3}{|c|}{ Uzun süre oyun oynadıktan sonra elim ağrıyor. } & 0,16 \\
\hline Evet & $11(27,5)$ & $6(15,0)$ & \\
\hline Hayır & $13(32,5)$ & $21(52,5)$ & \\
\hline Nadiren & $16(40,0)$ & $13(32,5)$ & \\
\hline \multicolumn{3}{|c|}{ Oyun oynarken el bileğimde elektrik çarpar tarzda ağrı oluyor. } & 0,28 \\
\hline Evet & $4(10,0)$ & $1(2,5)$ & \\
\hline Hayır & $31(77,5)$ & $31(77,5)$ & \\
\hline Nadiren & $5(12,5)$ & $8(20,0)$ & \\
\hline
\end{tabular}




\begin{tabular}{|c|c|c|c|}
\hline \multicolumn{3}{|c|}{ Oyun oynarken elimin uyuştuğunu hissediyorum. } & \multirow[t]{2}{*}{0,22} \\
\hline Evet & $11(27,5)$ & $6(15,0)$ & \\
\hline Hayır & $14(35,0)$ & $21(52,5)$ & \\
\hline Nadiren & $15(37,5)$ & $13(32,5)$ & \\
\hline \multicolumn{3}{|c|}{ Oyun oynarken parmaklardan koluma doğru yayılan bir ağrı hissediyorum. } & 0,92 \\
\hline Evet & $4(10,0)$ & $5(12,5)$ & \\
\hline Hayır & $26(65,0)$ & $26(65,0)$ & \\
\hline Nadiren & $10(25,0)$ & $9(22,5)$ & \\
\hline \multicolumn{3}{|c|}{ Oyun oynarken omzumda ağrı hissediyorum. } & 0,23 \\
\hline Evet & $5(12,5)$ & $11(27,5)$ & \\
\hline Hayır & $23(57,5)$ & $18(45,0)$ & \\
\hline Nadiren & $12(30,0)$ & $11(27,5)$ & \\
\hline \multicolumn{3}{|c|}{ Oyun oynarken mouse/joystick/telefon kavramada zorlanıyorum. } & 0,14 \\
\hline Evet & $6(15,0)$ & $1(2,5)$ & \\
\hline Hayır & $32(80,0)$ & $37(92,5)$ & \\
\hline Nadiren & $2(5,0)$ & $2(5,0)$ & \\
\hline \multicolumn{3}{|c|}{ Yazı yazarken zorlanıyorum. } & 0,52 \\
\hline Evet & $1(2,5)$ & $2(5,0)$ & \\
\hline Hayır & $27(67,5)$ & $30(75,0)$ & \\
\hline Nadiren & $12(30,0)$ & $8(20,0)$ & \\
\hline \multicolumn{3}{|c|}{ Şişe, bardak vb. kaldıırken zorlanıyorum. } & 0,38 \\
\hline Evet & $1(2,5)$ & $1(2,5)$ & \\
\hline Hayır & $35(87,5)$ & $38(95,0)$ & \\
\hline Nadiren & $4(10,0)$ & $1(2,5)$ & \\
\hline \multicolumn{3}{|c|}{ El veya el bileğimde güçsüzlük hissediyorum. } & 0,53 \\
\hline Evet & $4(10,0)$ & $6(15,0)$ & \\
\hline Hayır & $29(72,5)$ & $30(75,0)$ & \\
\hline Nadiren & $7(17,5)$ & $4(10,0)$ & \\
\hline \multicolumn{3}{|c|}{ Oyun oynarken ağrılarımı umursamıyorum. } & $0,01^{*}$ \\
\hline Evet & $8(20,0)$ & $20(50,0)$ & \\
\hline Hayır & $28(70,0)$ & $15(37,5)$ & \\
\hline Nadiren & $4(10,0)$ & $5(12,5)$ & \\
\hline \multicolumn{3}{|c|}{ Geceleri ellerimde veya kolumda çok ağrı oluyor. } & 0,45 \\
\hline Evet & $2(5,0)$ & $2(5,0)$ & \\
\hline Hayır & $34(85,0)$ & $30(75,0)$ & \\
\hline Nadiren & $4(10,0)$ & $8(20,0)$ & \\
\hline \multicolumn{3}{|c|}{ Oyun oynarken bacaklarımda ağrı hissediyorum. } & 0,90 \\
\hline Evet & $3(7,5)$ & $4(10,0)$ & \\
\hline Hayır & $28(70,0)$ & $28(70,0)$ & \\
\hline Nadiren & $9(22,5)$ & $8(20,0)$ & \\
\hline \multicolumn{3}{|c|}{ Oyun oynarken bacaklarımda karıncalanma/uyuşukluk hissediyorum. } & 0,60 \\
\hline Evet & $7(17,5)$ & $7(17,5)$ & \\
\hline Hayır & $22(55,0)$ & $18(45,0)$ & \\
\hline Nadiren & $11(27,5)$ & $15(37,5)$ & \\
\hline \multicolumn{3}{|c|}{ Oyun oynarken bacağıma kramplar giriyor. } & 0,82 \\
\hline Evet & $2(5,0)$ & $2(5,0)$ & \\
\hline Hayır & $31(77,5)$ & $33(82,5)$ & \\
\hline Nadiren & $7(17,5)$ & $5(12,5)$ & \\
\hline \multicolumn{3}{|c|}{ Geceleri bacağımda ağrı hissediyorum. } & 0,84 \\
\hline Evet & $3(7,5)$ & $2(5,0)$ & \\
\hline Hayır & $28(70,0)$ & $30(75,0)$ & \\
\hline Nadiren & $9(22,5)$ & $8(20,0)$ & \\
\hline \multicolumn{3}{|c|}{ Günlük hayatta merdiven inip çıkmakta zorlanıyorum. } & 0,80 \\
\hline Evet & $5(12,5)$ & $6(15,0)$ & \\
\hline
\end{tabular}




\begin{tabular}{|c|c|c|c|}
\hline Hayır & $28(70,0)$ & $29(72,5)$ & \\
\hline Nadiren & $7(17,5)$ & $5(12,5)$ & \\
\hline \multicolumn{3}{|c|}{ Oyun oynarken bacaklarımı hareket ettirme ihtiyacı hissediyorum. } & 0,30 \\
\hline Evet & $9(22,5)$ & $15(37,5)$ & \\
\hline Hayır & $19(47,5)$ & $17(42,5)$ & \\
\hline Nadiren & $12(30,0)$ & $8(20,0)$ & \\
\hline \multicolumn{3}{|c|}{ Oyun oynarken bacaklarımda tutukluk hissediyorum. } & 0,69 \\
\hline Evet & $4(10,0)$ & $2(5,0)$ & \\
\hline Hayır & $31(77,5)$ & $33(82,5)$ & \\
\hline Nadiren & $5(12,5)$ & $5(12,5)$ & \\
\hline \multicolumn{3}{|c|}{ Oyundan kalkarken dizlerimden çıtırtı sesleri duyuyorum. } & 0,35 \\
\hline Evet & $5(12,5)$ & $10(25,0)$ & \\
\hline Hayır & $28(70,0)$ & $24(60,0)$ & \\
\hline Nadiren & $7(17,5)$ & $6(15,0)$ & \\
\hline \multicolumn{3}{|c|}{ Oyun oynarken sırtımın ağrıdığını hissediyorum. } & 0,13 \\
\hline Evet & $8(20,0)$ & $16(40,0)$ & \\
\hline Hayır & $17(42,5)$ & $14(35,0)$ & \\
\hline Nadiren & $15(37,5)$ & $10(25,0)$ & \\
\hline \multicolumn{3}{|c|}{ Oyun oynarken duruşumun bozulduğunu hissediyorum. } & $0,03^{*}$ \\
\hline Evet & $12(30,0)$ & $23(57,5)$ & \\
\hline Hayır & $17(42,5)$ & $12(30,0)$ & \\
\hline Nadiren & $11(27,5)$ & $5(12,5)$ & \\
\hline \multicolumn{3}{|c|}{ Oyun oynarken belimden kalçama doğru ağrı hissederim. } & 0,96 \\
\hline Evet & $7(17,5)$ & $7(17,5)$ & \\
\hline Hayır & $24(60,0)$ & $25(62,5)$ & \\
\hline Nadiren & $9(22,5)$ & $8(20,0)$ & \\
\hline \multicolumn{3}{|c|}{ Beden eğitimi dersinde arkadaşlarımdan daha çok zorlanıyorum. } & 0,39 \\
\hline Evet & $4(10,0)$ & $3(7,5)$ & \\
\hline Hayır & $33(82,5)$ & $33(75,0)$ & \\
\hline Nadiren & $3(7,5)$ & $7(17,5)$ & \\
\hline \multicolumn{3}{|c|}{ Oyun oynamaya başladıktan bir süre sonra boynumun ağrıdığını hissediyorum. } & 0,50 \\
\hline Evet & $13(32,5)$ & $15(37,5)$ & \\
\hline Hayır & $20(50,0)$ & $15(37,5)$ & \\
\hline Nadiren & $7(17,5)$ & $10(25,0)$ & \\
\hline \multicolumn{3}{|c|}{$\begin{array}{l}\text { Boynum ağrıdığı için ders çalışırken veya günlük yaşamda başka şeyler } \\
\text { yaparken zorlanıyorum. }\end{array}$} & 0,65 \\
\hline Evet & $6(15,0)$ & $8(20,0)$ & \\
\hline Hayır & $27(67,5)$ & $23(57,5)$ & \\
\hline Nadiren & $7(17,5)$ & $9(22,5)$ & \\
\hline \multicolumn{3}{|c|}{ Boynum ağrıdığı için yatarken rahat bir pozisyon bulmakta zorluk çekiyorum. } & 0,55 \\
\hline Evet & $7(17,5)$ & $4(10,0)$ & \\
\hline Hayır & $26(65,0)$ & $30(75,0)$ & \\
\hline Nadiren & $7(17,5)$ & $6(15,0)$ & \\
\hline
\end{tabular}

\section{Tartışma}

Çalışmamı sonucunda, IOOB tanısı olan ve olmayan sağlıklı ergenler arasında kas iskelet sistemi semptomları açısından anlamlı bir fark bulunmamıştır. Yalnızca oyun oynarken duruşunun bozulduğunu daha fazla hisseden I00B tanısı olan adölesanların, kas iskelet sistemi semptomlarını sağlıklıara göre daha az önemsedikleri saptanmıştır. Bu nedenle çalışma sonuçları yorumlanırken IOOB tanısı olan ergenlerin, semptomlarını gerçekçi bir şekilde rapor edememiş olma durumları göz önünde bulundurulmalıdır. Aydoğdu, boş zamanlarının iki ile beş saat arasındaki dilimini bilgisayarda ve internet başında geçiren 
erkeklerin $(\% 57,7)$ ve kızların $(\% 42,3)$ oyun oynadığını tespit etmiştir $(9)$. Paulus ve arkadaşları, yaptıkları sistematik derlemede çocuk ve adölesanlarda internet oyun oynama bozukluğunun erkeklerde kızlara göre beş kat daha fazla olduğunu belirtmiştir (10). Bu çalışmada ise IOOB tanısı olan adölesanlarda erkeklerin prevalansı daha fazla olsa da sağ|ıklı gruba göre cinsiyetler arasında bir farklılık bulunmamıştır.

Bilgisayar oyunları, özellikle ergenlik çağındaki gençler arasında görülen sırt ağrısının bir belirleyicisi olarak tanımlanmıştır (11). Mustafaoğlu ve arkadaşlarının yaptığı çalışmada, dijital oyun oynamanın, omurga, omuz ve el bileğinde kas iskelet sistemi problemlerine neden olabileceği belirtilmiştir (12). Bir başka çalışmada aşırı ve/veya problematik internet kullanımının ve oyun oynamanın boyun ve sırt ağrısına neden olabileceği vurgulanmıştır (13). Bu çalışmanın sonucunda ise, diğer çalışmalardan farklı olarak iOOB tanısı olan adölesanların oyun oynama sırasında kas iskelet sistemi semptomlarına önem vermedikleri tespit edilmiştir.

Literatürde, uzun süreli video oyun oynama ile postürel problem arasında korelasyonun varlığı bildirilmiştir. Straker ve arkadaşlarının yaptıkları çalışmada, çocuklarda tablet kullanımının masaüstü bilgisayar kullanımına göre gövdede daha fazla fleksiyon ve asimetrik pozisyona, omuzlarda daha fazla fleksiyon ve elevasyon pozisyonuna, boyun çevresi kaslarda ise artmış aktiviteye neden olduğu saptanmıştır (14). Literatür ile paralel olarak bu çalışmada, IOOB tanısı olan adölesanların oyun oynama sırasında duruşlarının bozulduğunu sağlıkı adölesanlara göre daha fazla bildirdiği gözlemlenmiş̧tir.

Bu çalışmada, IOOB tanısı almış adölesanların kas iskelet sistemi problemlerinin ayrıntılı olarak sorgulanması ve sağlıklı adölesanlarla karşılaştırma yaparak aradaki farkı ortaya koyması çalışmanın güçlü yanlarını oluşturmaktadır. Diğer taraftan, oyun oynama süresinin sorgulanmamış olması ve subjektif değerlendirme yöntemleri kullanılmış olması çalışmamızın limitasyonları arasında yer almaktadır.

Çalışma sonuçları incelendiğinde, IOOB tanılı ve sağlıklı adölesanlar arasında kas iskelet sistemi semptomları açısından anlamlı bir farklılık olmadığı görülmüştür. IOOB tanılı adölesanlar sağlıklıara göre oyun oynama sırasında daha fazla postürel bozukluk rapor etse de kas iskelet sistemi semptomlarını daha az önemsedikleri ortaya konmuştur. Sonuç olarak, kas iskelet sistemi semptomları açısından farklıık bulunmasa da oyun oynama sıklığı benzer olan sağlıklı adölesanlarla aynı riskle karşı karşıya olan í00B tanılı adölesanlarda, uzun süreli internette oyun oynama sonucunda oluşabilecek problemler ve korunma yöntemleri hakkında çocukların ve ailelerin bilgilendirilmesi ve farkındalıklarının artırıması gerekmektedir. IOOB tanısı olan adölesanların, oyun oynarken geçirdikleri sürenin fiziksel aktiviteye doğru aktarılması ve bu süre boyunca ergonomik koşullarının sağlanması önerilmektedir. I00B tanısı olan adölesanlarda kas iskelet semptomlarını değerlendirmek için objektif cihazlar kullanan ileri çalışmalara intiyaç vardır.

\section{Kaynaklar}

1. Lee SY, Lee HK, Choo H. Typology of internet gaming disorder and its clinical implications. Psychiatry Clin Neurosci 2017; 71(7): 479-491.

2. Liang J, Matheson BE, Kaye WH, Boutelle KN. Neurocognitive correlates of obesity and obesity-related behaviors in children and adolescents. Int J Obes (Lond) 2014; 38(4): 494-506.

3. American Psychiatric Association. Diagnostic and Statistical Manual of Mental Disorders, 5th. edition (DSM-5). Washington, DC. American Psychiatric Association; 2013

4. Mustafaoğlu R., Zirek E, Yasacı Z, Özdinçler A. Dijital teknoloji kullanımının çocukların gelişimi ve sağlığı üzerine olumsuz etkileri. Addicta: The Turkish Journal on Addictions 2018; 5(2): 227-247.

5. Harris C, Straker L, Pollock C, Smith A. Children, computer exposure and musculoskeletal outcomes: the development of pathway models for school and home computer-related musculoskeletal outcomes. Ergonomics 2015; 58(10): 1611-1623.

6. $\mathrm{Ko} \mathrm{CH}$, Lin HC, Lin PC, Yen JY. Validity, functional impairment and complications related to Internet gaming disorder in the DSM-5 and gaming disorder in the ICD-11. Aust N Z J Psychiatry 2020; 54(7): 707-718.

7. Young KS. Internet addiction: The emergence of a new clinical disorder. Cyberpsychol Behav 1998; 1: 237 244.

8. Bayraktar F, Gün Z. Incidence and correlates of internet usage among adolescents in North Cyprus. Cyberpsychol Behav 2007; 10: 191-197. 
9. Aydoğdu-Karaaslan í. Dijital oyunlar ve dijital şiddet farkındalığl: ebeveyn ve çocuklar üzerinde yapılan karşılaşıırmalı bir analiz. Uluslararası Sosyal Araştırmalar Dergisi 2015; 8(36): 806-818.

10. Paulus FW, Ohmann S, von Gontard A, Popow C. Internet gaming disorder in children and adolescents: a systematic review. Dev Med Child Neurol 2018; 60(7): 645-659.

11. Hellström C. Online gaming in relation to negative consequences and ill health among adolescents. Licentiate Exam, Uppsala: Uppsala University Faculty of Medicine, Department of Public Health and Caring Sciences, 2013.

12. Mustafaoglu R, Yasacı Z. Dijital oyun oynamanın çocukların ruhsal ve fiziksel sağlığı üzerine olumsuz etkileri. Bağımlılık Dergisi 2018; 19(3): 51-58.

13. Ayenigbara 10. Gaming disorder and effects of gaming on health: an overview. Journal of Addiction Medicine and Therapeutic Science 2018; 4(1): 1-3.

14. Straker LM, Coleman J, Skoss R, et al. A comparison of posture and muscle activity during tablet computer, desktop computer and paper use by young children, Ergonomics 2008; 51(4): 540-555. 